Original Research Article in Journal of Biosocial Science

Author Version

\title{
Men's Attitudes about Abortion in Uganda
}

\author{
Ann M. Moore ${ }^{1}$, Gabriel Jagwe-Wadda ${ }^{2}$, and Akinrinola Bankole ${ }^{3}$ \\ ${ }^{1}$ Corresponding author: Senior Research Associate, Guttmacher Institute, NY, \\ NY, USA \\ ${ }^{2}$ Deceased, last position was as Lecturer, Department of Sociology, Faculty of \\ Social Sciences, Makerere University, Kampala, Uganda \\ ${ }^{3}$ Director of International Research, Guttmacher Institute, NY, NY, USA
}

doi:10.1017/S0021932010000507

Published in Journal of Biosocial Science (2011), 43, pp 31-45

Published online: 17 Sep 2010

Abstract available on Journal of Biosocial Science website here. 


\section{Summary}

Abortion is illegal in Uganda except to save the life of the woman. Nevertheless, the practice is quite common: About 300,000 induced abortions occur annually among Ugandan women aged 15-49 (Singh et al., 2005) and a large proportion of these women require treatment for postabortion complications. In a male dominant culture as exists in Uganda where men control most of the financial resources, men play a critical part in determining whether women receive a safe abortion or appropriate treatment if they experience abortion complications. This study examines men's role in determining women's access to a safer ${ }^{1}$ abortion and postabortion care. It draws on in-depth interviews (IDIs) carried out in 2003 with 61 women aged 18-60 and 21 men aged 20-50 from Kampala and Mbarara, Uganda. Respondents' descriptions of men's involvement in women's abortion care agreed: Men's stated attitudes about abortion often prevented women from involving them in either the abortion or postabortion care. Most men believe that if a woman is having an abortion, it must be because she is pregnant with another man's child although this does not correspond with women's reasons for having an abortion--a critical disjuncture revealed by the data between men's perceptions of and women's realities regarding reasons for seeking an abortion. If the woman does experience postabortion complications, the prevailing attitude among men in the sample was that they cannot support a woman in such a situation seeking care because if it had been his child, she

\footnotetext{
${ }^{1}$ By using the term "safer," we mean to identify an abortion that is less likely to result in abortion complications. We do not use the term safe because even access to resources does not guarantee a safe abortion in Uganda.
} 
would not have had a covert abortion. Since money is critical to accessing appropriate care, without men's support, women seeking an abortion may not be able to access safer abortion options and if they experience complications, they may delay care-seeking or may not obtain care at all. Barriers to involving men in abortion decision-making endanger women's health and possibly their lives. 


\section{Introduction}

Uganda is one of the poorest countries in the world with a per capita annual income of US $\$ 340$ (World Bank, 2009). More than $85 \%$ of the population lives in rural areas, making it one of the least urbanized countries in sub-Saharan Africa (World Bank, 2009). The average family size is about 6.7 children per woman; however, the desired family size is lower (5.0 for women and 5.8 for men) (Uganda Bureau of Statistics (UBOS) \& Macro, 2007). This means that women and their partners are finding it difficult to prevent the pregnancies they do not want either then or at all. Thirty-three percent of births and current pregnancies occurring between 2000/2001 and 2005/2006 were, according to the woman, wanted later and $13 \%$ were not wanted at all (UBOS \& Macro, 2007). This is because desired fertility has decreased more rapidly than the increase in contraceptive use. In 2005/2006, contraceptive use was low (24\% of currently married women and $54 \%$ of sexually active unmarried women were using a method with traditional methods accounting for $5.8 \%$ and $7.1 \%$ of this use, respectively), yet $41 \%$ of married women do not want a child soon, or at all, though they are not using an effective method of contraception (UBOS \& Macro, 2007). The high level of unmet need (41\%) signifies the proportion of the population at risk of an unintended pregnancy.

According to national law, abortion is illegal in Uganda except to save the life of the woman. The abortion law in Uganda is the result of laws promulgated by 
English colonizers in the nineteenth century. At that time, abortion was illegal in Europe and so the laws in the territories were a natural extension of the laws at home. Since then, abortion has been legalized in Europe, but the old laws have not been revised in this former colony (Brookman-Amissah \& Moyo, 2004). Very few abortions are performed legally under current restrictions. Nevertheless, the practice is quite common: About 300,000 induced abortions occur annually among Ugandan women aged 15-49, a rate of 54 abortions per 1,000 women (Singh et al., 2005) as compared to 19.4 abortions per 1,000 women in the United States (Facts, 2010). A large proportion of these abortions are carried out clandestinely and by unqualified providers under conditions deemed unsafe, that is using a procedure for terminating a pregnancy either by an unqualified individual or in an environment lacking minimal medical standards or both.

Virtually all of the abortions that were performed around the time of the Singh et al. 2005 study used dilation and curettage, vacuum aspiration, saline instillation, oral induction or insertion of a substance or object in the vaginal (Prada et al., 2005). Misoprostol, commonly identified as Cytotec, was not known or available in Uganda at the time the study was conducted, even on the black market. According to knowledgeable health professionals in Uganda, of the abortions which occur annually, $50 \%$ do not result in complications; $28 \%$ result in complications treated in a medical facility; and $22 \%$ result in complications that go untreated (Singh et al., 2006). This translates into an estimated 85,000 women (or 15 of every 1000 women of reproductive age) receiving treatment for 
complications from induced abortion in Ugandan health facilities each year (Singh et al., 2005).

Most abortion complication patients are treated in public facilities (Prada et al., 2005). Yet care is not always sought as quickly as it should be, resulting in more severe complications and further endangering the woman's health (Thaddeus \& Maine, 1994; Atuyambe et al., 2005). Evidence from health professionals knowledgeable about postabortion care shows that about $83 \%$ of urban nonpoor women (defined as those with income levels higher than average) and $70 \%$ of rural nonpoor women are likely to receive treatment for abortion complications they may experience. Sixty-two percent of urban poor women (defined as those with income levels lower than average) and $51 \%$ of rural poor women are perceived to obtain needed care (Prada et al., 2005). A large and unknown proportion of women experience complications from abortion for which they do not seek care.

A proportion of abortion complications, some of which get treatment and some of which do not, result in death. In 2005 , the national maternal mortality ratio was estimated by the World Health Organization to be 550 maternal deaths per 100,000 live births, making Uganda a country with relatively high maternal mortality (WHO, 2007a). About $26 \%$ of maternal deaths in Uganda have been estimated to be due to unsafe abortion (Road Map, 2008). While this estimate 
seems to be high, it is unlikely it is less than the $17 \%$ that the World Health Organization estimates for Eastern Africa (WHO, 2007b).

Much remains unknown about the antecedents to maternal morbidity and mortality in Uganda, but one of the factors that is often named by women is lack of funds to pay for medical care or transportation to the health facility (Weeks et al., 2005). Anthropological work on motherhood in Uganda demonstrates that pregnancy and all factors surrounding it are seen as a woman's responsibility as well as a test of her fortitude and strength, which may also contribute to women delaying abortion as well as care for postabortion complications (Kyomuhendo, 2003). Furthermore, social stigma surrounding abortion from members of the community and anticipation of abuse by medical personnel are yet more barriers to seeking safer abortions and care for abortion-related complications (Kyomuhendo, 2003). Finally, partners' attitudes and women's perceptions of partners' attitudes can delay or prevent women from seeking a safer abortion as well as seeking care for abortion complications if doing so might increase the probability that the partner would learn about the abortion (Jagwe-Wadda et al., 2006).

In Uganda, a traditional society where men are the heads of the household and control most of the household resources, men are in effect gatekeepers to accessing less dangerous abortions and postabortion care, if needed. Men have been for the most part neglected regarding their role in pregnancy prevention and 
resolution, especially in sub-Saharan Africa (Greene 2000); therefore very little is known about their attitudes and the role they play in women's reproductive health, and specifically, in abortion and postabortion care (Kaida et al., 2005). This article examines men's and women's perspectives on men's involvement in abortion decision-making and seeking postabortion care if complications from an unsafe abortion occur.

\section{Background}

The role male partners play in women's reproductive health takes place directly and indirectly, biologically and socially (Dudgeon \& Inhorn, 2004).

In relation to abortion, for example, in some countries women even need their husband's permission to have an abortion (Gürsoy, 1996). The relationship that the man has with the woman, i.e. whether the woman is his wife, mistress or

girlfriend, most likely influences his involvement as well as his desires regarding how to manage her reproductive health (Rausch \& Lyaruu, 2005). Whereas expectations about childbearing within marriage may lead a man to support his wife to carry a pregnancy to term, a man might encourage a girlfriend abort since social sanctions might be brought to bear on them for having a child out of wedlock.

Men play a critical role in reproductive decision-making in sub-Saharan Africa (Fayorsey, 1989; Mbizvo \& Adamchak, 1999). In the minimal work which has 
been done with men on abortion in Africa, research has identified men's opposition to abortion spanning the continent. A recent qualitative exploration of men's attitudes and involvement in abortion in Burkina Faso found that men do not want women to have abortions. As a consequence, women have them secretly so as to minimize difficulties that could accompany telling the man about the abortion (Rossier, 2007). Qualitative data collected with men in Zimbabwe found that men viewed abortion as a sign of illicit sexual activity (Chikovore et al., 2002). These authors framed men's attitudes towards abortion within men's attitudes towards control over women and concluded that men felt anxious and vulnerable regarding their role in society due to shifting gender roles and greater rights accorded to women. Abortion, as a concrete manifestation of the shift towards smaller families and greater female autonomy, is the site of a great deal of social tension. One of the reasons women said they did not disclose their abortion intentions or experiences to their male partners was because they feared violence (Chikovore et al., 2002).

In the only research done to date with men in Uganda on abortion, Nyanzi et al. found that due to abortion's legal status in the country, their respondents, motorbike taxi drivers, felt it necessary to dissociate themselves from the practice in public spaces (2005). Yet in private spaces they reported being involved in abortions. This notwithstanding, the motorbike taxi drivers expressed a great deal of tension and conflict over abortion as it relates to notions of respectability, family and shame. The study participants reported that relationships do not 
survive the event of an abortion due to guilt, broken trust and inherent conflict (Nyanzi et al., 2005).

The research project under which these data were collected set out to understand how women in a setting such as Uganda where abortion is highly restricted and the abortion rate is high, attempt to induce abortion and if complications ensue, how they go about seeking postabortion care, if at all. The motivation behind the study was to try to capture abortion complications among women who never make it to a health care facility to treat their postabortion complications. What became apparent when analyzing the data is the critical role men play in determining women's access to a less dangerous abortion as well as appropriate and timely postabortion care. Men, as key gatekeepers to abortion and abortion-related care in Uganda, is the subject of this analysis.

\section{Methods}

This report draws on data collected via in-depth interviews (IDIs) carried out in 2003 with women and men who reside in Kampala, an urban district and the capital city of Uganda, and Mbarara, a largely rural district in the west. In each district, one subcounty/division was selected at random and within each subcounty, two parishes were selected. Households who had women and men residing in them between the ages of $18-60$ were identified with the assistance of women community leaders. Once households were identified, the study 
coordinator (one of the co-authors, GJW) arbitrarily selected potential respondents. Less than one in 10 respondents who were approached to participate in the in-depth interviews refused to participate. The refusals were from individuals who were engaged in an activity at the time they were approached such as tending a shop or farming. In Kampala, the data were collected in the Luganda language and in Mbarara, the data were collected in the Runyankole language. All of the interviewers were graduates from the Department of Sociology, Makerere University, with backgrounds in social science research methods and field experience in qualitative data collection who were adequately trained on administering the in-depth interview guide.

61 women aged $18-60$ and 21 men aged $20-50$ were interviewed. The interviewer obtained informed consent from each respondent before proceeding with the interview. On average, the IDIs took between 30 and 60 minutes. Within this sample, the men were better educated than the women, most of the sample was married/in a union and Christian (see Table 1).

\section{INSERT TABLE 1 HERE}

The IDIs asked about respondents' personal experiences with abortion and abortion complications as well as about the abortion experiences of community members including men's attitudes towards abortion, men's reactions to women who have abortions, men's role in helping women have abortions and treat 
abortion complications, and what men could do to help women avoid health complications from unsafe abortion. As can be seen from the topics of the IDIs, this work does not deal with reasons for unintended pregnancy or the reason for seeking an abortion. It is focused on the abortion experience exclusively.

The taped interviews were transcribed by hand, first into the language in which they took place and then translated into English. This process is of course vulnerable to the introduction of ambiguity and even errors either through incorrect transcription or through inaccurate translation (because the word or concept does not exist in English, the intended meaning in the local language was not clear or because the translator chose the wrong word when an adequate word does exist). This inevitable weakness is intrinsic to any data collection done in a language different than the language of analysis.

The English translations were reviewed for accuracy and completeness by the study coordinator before they were entered into a word processing document. The text was coded by the interviewers using N6 qualitative software (QSR, Melbourne, Australia, 2001). The main issues explored were outlined in the coding (node) structure, and analyses were conducted on the relevant nodes. Two authors (GJW and AMM) reviewed each other's analyses to ensure consistency and agreement on interpretation of the results. The paper draws almost exclusively on the quotes from men. The quotes are identified specifying residence (rural/urban), age, religion, highest level of education achieved, marital 
status, and number of children (parity for the woman, or number of children the man has fathered that resulted in a live birth).

\section{Results}

\section{Men's attitudes toward abortion}

When questioned generally about men's attitudes towards abortion, male respondents stated that men are not supportive of women having abortions. The reasons they give for being against women having abortions is that they do not agree with the practice; they believe that the aborted child could be an important member of society; that the woman could die undergoing the abortion, and they fear that they themselves might be arrested. As was found by Chikovore et al. in Zimbabwe (2002), men stated that if a woman is having an abortion, it must be because she is trying to evidence of an affair. Other reasons that came up less frequently were that poor men feared having to bear the costs of abortion and treatment for abortion complications; it may be the woman's only opportunity to have a child; and men who have AIDS would like to have three or four children before they die.

Interviewer (I): Do you think men in this community are supportive of a woman's desire to stop a pregnancy?

Respondent (R): No, they are not supportive because one who aborts could die and more so, the aborted baby is also a human being. 
—Rural male aged 28, Muslim, Primary 5, Married, 8 children

Some men want children and getting a child is not something easy. Some men die without producing a single child. Some men want babies and if a woman gives birth, he feels proud to get someone to call him "Father."

_Urban male aged 32, Protestant, Primary 7, Married, 4 children

Men's responses largely reflect the prevailing socio-cultural norms and values, influenced by religion, and the legal environment, all of which are strongly against abortion. However, men made an exception for young women in school. Consistent with Nyanzi et al.'s findings, the majority of men believed it to be acceptable for schoolgirls to get an abortion (2005). Men's support for abortion under this circumstance seemed to be largely motivated by self-interest as the reason men gave for being in support of a schoolgirl's abortion was that the man responsible could be brought up on defilement (rape) charges if the schoolgirl is found to be pregnant as the age of consent in Uganda is 18 (Nyanzi et al., 2005). Notably absent in their justification was that the girl should be given an opportunity to continue school since pregnant girls are expelled from school.

Women's secrecy around abortion

The social stigma against abortion for anyone but schoolgirls as well as the pronatalist outlook held by most Ugandans, particularly among men towards childbearing within marriage, can serve as a disincentive for a woman to speak 
with her partner about abortion. The perception held by both men and women in the sample was that women frequently do not let their partners know about abortions, and that the greatest secrecy is exercised within marriage.

I: Do women discuss with their husbands or partners about their unwanted pregnancy?

$R:$ It is not common for your wife to tell you. Maybe if she is a prostitute/concubine. She can tell you, "I did not want this pregnancy so let us abort." But for a woman who you married and stay within the home, she cannot tell you about aborting.

--Rural male aged 43, Catholic, education not specified, Married, 6 children

Women respondents described abortion as the woman's secret. One woman who helped her friend abort explained how they kept the secret from her partner:

I: Did the man who impregnated her come to know that she aborted? R: We planned and deceived him. Before she aborted, she got some fever and the man knew about it. After she aborted we told him that she had a miscarriage. --Rural female aged 50, Muslim, Primary 6, Married, 10 children

Similar to women's experiences in Burkina Faso (Rossier, 2007), women in Uganda, such as the situation related above, are inclined to keep the abortion a secret to minimize problems that may come with telling the man. 
Men's involvement in postabortion care

Approximately half of women who obtain abortions in Uganda will need postabortion care in her lifetime (Singh et al., 2006). (For an explanation of common abortion complications in Uganda, see Prada et al., 2005.) Since many women keep abortion a secret, men described how they may not even know that a woman is experiencing abortion complications.

I: What do men do when their wives/partners experience health problems after stopping a pregnancy?

R: Many men don't get to know that their women are having complications resulting from stopping a pregnancy. They only see the women sick, thinking it's malaria. This causes the woman many problems and she can even die. She can be given treatment for malaria and the real complication isn't treated at all. --Urban male aged 44, Catholic, Primary 5, Married, 5 children

As this quote demonstrates, some women maintain their secret of having had an abortion even while obtaining treatment-underscoring the severity of the consequences women perceive may come about as a result of having had an abortion. This desperation to keep an abortion a secret is also one of the primary reasons respondents said that women delay seeking care for complications. 
If a woman who did not involve her partner begins to experience complications, not only does she have to weigh the consequences of revealing that she has had an abortion but at that point, it also becomes unavoidable to reveal that she made the decision to have an abortion without informing her partner. The primary reason men and women gave for women telling men about abortion complications was because of the need to get money from him to help pay for treating the complications. It is possible that a woman may be able to secure financial support from other sources than their partner to treat abortion complications, either through her own income or through the assistance of others. Yet in a country as poor as Uganda, there are very few who have any resources to spare. Women who have the assistance of their male partners are much more likely to be able to get safer abortions and appropriately treat their abortion complications. Having money was specified as a prerequisite to getting treated at clinics (private health units) and respondents said that money also speeds up the treatment one receives at the hospital (public health units where treatment is supposed to be free). While cost estimates were made conditional on the type of complication the woman was experiencing, they ranged from 3,000 Ugandan shillings to 200,000 Ugandan shillings (equal to about US $\$ 1.50$ to US\$110 in 2003 dollars).

If the woman chooses not to reveal, she can try to self-treat her complications, most likely through the use of traditional, less effective methods. Women respondents, as well as women they knew about who had postabortion 
complications, related adopting a wait and see approach in the hopes that they would not have to reveal their abortion to their partner. While the woman is waiting to see if she'll get better, her health, her future fertility and even her life are being threatened. Just a Chikovore et al. identified in Zimbabwe, but which applies to the Ugandan just as well, "The silence and secrecy imply that abortions and related complications and even death may occur without men knowing the cause" (2002, pg. 329).

Men unequivocally stated that if the man finds out that the woman terminated a pregnancy without his knowledge, he cannot support her no matter what health problems she experiences. Part of the perceived offence was that the woman has done something abominable, since abortion is highly stigmatized and seen as something evil. Further offence was taken at terminating a pregnancy that the man may have wanted. (As was presented in the introduction, men and women differ on ideal family size in Uganda with men wanting, on average, 0.8 more children than women (UBOS \& Macro, 2007)). Men also perceived that a woman having a secret abortion must be trying to hide the evidence of an affair. Lastly, men also expressed unhappiness that a woman would make a decision to have an abortion without consulting them.

I: Now during that time when the man figures out that the woman has developed these complications, how does he support the woman? 
$R$ : In our culture here, when the woman develops these complications when she didn't inform her husband, then the man may even separate with the woman or the man may opt not to support the woman in any way and the woman has to support herself.

--Urban male aged 50, Catholic, Senior 4, Married, 4 children

Not having money was mentioned by a couple of men as a reason why males may not provide support for partners who experience abortion complications. Men explained that sometimes men even deny responsibility for the pregnancy because they do not have money to help the woman with postabortion complications. This adds emotional injury to physical injury as it is socially disgraceful to have the man deny responsibility since it implies that the woman had additional sexual partners.

Numerous men interpreted the fact that a woman had an abortion as a sign that she did not love her partner anymore as evidenced by the fact that she did not want to have a(nother) child with him. Men used this as another justification for not supporting a woman if she experiences complications.

I: What do men do when their wives/partners experience health problems after stopping a pregnancy?

$R$ : It depends on whether you agreed upon having the abortion or not. If you agreed, you try to buy her food and drinks to restore her energy. If you did not 
agree to have an abortion, she takes the responsibility for her action because that means she doesn't want you anymore.

--Rural male aged 43, Catholic, education not specified, Married, 6 children

I: What do men do when their wives experience health problems after stopping a pregnancy?

$R$ : Some men usually send these partners to their homes [parents' home].

I: Why?

$R$ : Because since this woman is not willing to produce my child then the best thing is for her to go back to her parents.

--Urban male aged 22, Bahai Faith, Primary 7, Separated, 1 child who died

Yet women's reasons for having abortions did not adhere to men's perceptions of infidelity or lack of women's interest in their partner. The women in the sample who had experienced an unwanted pregnancy explained that their previous child was still young, she was in school, and that she had a conflict-filled relationship with her husband. Women stated that women may decide to keep the abortion secret because they figure other people, including her partner, are not likely to see the need for the abortion. This research thereby uncovers a disjuncture between the perceptions of men and the realities of women regarding why a woman may choose to terminate a pregnancy. That misunderstanding holds serious consequences for the woman's health as it directly impacts her 
willingness to involve her partner in her abortion experience, exposing her to riskier health consequences.

Conditions under which men are supportive

While male respondents did not uniformly present men as barriers to women's health care access, they presented, at best, scenarios of men's involvement that were highly conditional. In cases where men have a prior knowledge of the abortion or are involved in the decision-making, they described helping women make doctors' appointments, providing financial support such as buying her medicine, arranging for transportation or taking her to a facility for treatment, and buying her food.

For me, if I agree with my partner to abort...I go to the clinic/hospital and buy her medicine. If it requires taking her to the hospital I take her. If it requires buying her energy building foods, I can buy them.

--Rural male aged 43, Catholic, education not specified, Married, 6 children

As a man, if you really love your wife, especially those who are married, the man has that duty to support the women in this matter. You have to seek treatment for her. You don't just leave her to seek treatment herself. You don't just leave her like that! This is one of the responsibilities of the husband in the home. —Urban male aged 40, Protestant, Senior 6, Married, 3 children 
As this quote demonstrates, men's sense of responsibility to the woman experiencing abortion complications may be conditioned on to their relationship to the woman (see also Rauch \& Lyarru, 2005).

\section{Discussion}

In Uganda, abortion culturally challenges women's predominant identity of being a mother. Abortion is a threat to pronatalism and secret abortion is a threat to men's dominance in the home. In a situation such as Uganda where abortions are almost always carried out illegally, as was found in Zimbabwe by Chikovore et al. (2002), not being able to get the man's financial and logistical support for carrying out the abortion increases the probability that the woman will have to resort to a less safe abortion which increases her chances of getting complications. As in Zimbabwe, men in Uganda interpreted abortion to be a sign of infidelity and as such, they said they could not support a woman seeking an abortion or suffering complications. Chikovore et al. (2002) concluded, in the case of Zimbabwe, that this demonstrates married men are more concerned with women's sexuality and their own feelings of vulnerability and lack of control over

female sexuality than they are with women's health. Similarly, in Uganda, the fact that men categorically said they could not support a woman requiring postabortion care who had had an abortion without their knowledge and consent also demonstrates a prioritization among Ugandan men in our sample of control over female sexuality that trumps possibly saving that woman's life. 
While it is possible that men were expressing more rigid anti-abortion sentiments than they actually held to distance themselves from abortion, men's anti-abortion sentiments and subsequent behaviors were verified by the women interviewed in the sample. Men's expressed stand on this issue may also reflect their tendency to see themselves as the custodians and enforcers of the cultural norms and values in a largely patriarchal society like Uganda, especially if they perceive that tradition is being undermined by women rejecting traditional roles of reproduction. Whether men's stated opposition to abortion as well as their stated unwillingness to help a woman with postabortion complications in fact dictates their behavior when confronted with such a situation is unknown. The dangers of this discourse are that women may never find out how their partner may react to an abortion since, based on men's discourse, women may choose not to involve their partner either in trying to procure an abortion or manage postabortion complications and as a consequence, experience serious health problems. If men expressed more comprehension of women's abortion-related choices, then perhaps fewer women would feel compelled to resort to secrecy regarding their abortion. Yet until men are willing to support women's choices, this secrecy may be essential to protect women's access to abortion.

These data point to the disjuncture between men's perceptions of why a woman would have an abortion and women's reasons for seeking an abortion. Men's misperceptions seem to prevent them from supporting women's abortion or 
abortion-care seeking. Educating men about women's burdens, fears, and constraints that lead them to elect to have an abortion has the potential to engender greater comprehension among men of women's abortion decisionmaking. Whether this compassion might lead to men's increased involvement in women's abortion care is unknown.

Chikovore et al. (2002) point out that women's silence around their abortion experiences misses an important demonstration of how women exercise their agency. "Without disregarding the vulnerability of women and the male violence within patriarchal structures, emphasizing women's powerlessness risks concealing other capabilities of women, which can be the basis for promoting women's health" (pg. 329). Women's experiences of clandestine abortion seeking, resourceful pursuit of postabortion care and the use of girlfriends and other female family members to carry this out (Jagwe-Wadda et al., 2006) is a demonstration of women's agency as a subversion of men's domination that can be easily overlooked because of women's fear in speaking about abortion.

\section{Conclusion}

This paper what is known about men's involvement in abortion and postabortion care in a setting where abortion is mostly illegal. Dudgeon and Inhorn's review of male involvement in women's reproductive health did not discuss men's involvement in women's access to safe abortion or appropriate postabortion care 
(Dudgeon \& Inhorn, 2004). Nyanzi et al.'s article did not examine postabortion care (2005). And while this paper did not directly treat Kyomuhendo's theory that in Uganda, all pregnancy-related problems are treated as a woman's fault and a sign of her failing, the fact that men were so quick to absolve themselves of any responsibility related to women experiencing abortion complications lends further credence to her work.

In the patriarchal social structure present in Uganda, rules governing women's access to abortion are subject to the perceptions of abortion as envisioned by predominantly male policymakers, service providers and, of course, husbands. Abortion is roundly condemned by the prevailing religions on Uganda, as well as the firmly pronatalist culture which ascribes preeminent social value to having children. The discourse men used to justify their disapproval of abortion was grounded in cultural values and religious terminology. The language men used to describe their opposition to abortion was so uniform, it bespeaks the effectiveness of religious and cultural messages which condemn abortion.

Men have been largely ignored as agents in the reproductive health sphere (Greene 2000). The necessity of involving men in reproductive health programs was reinforced at the International Conference on Population and Development held in Cairo in 1994, at the Fourth World Conference on Women held in Beijing the following year (Family Care International (FCI), 1999), and domestically, in Uganda's 1995 National Population Policy held that same year (Ministry of 
Finance and Economic Planning, 1995). The neglect of men as agents and clients of family planning has been identified as a cause of the limited impact of many family planning programs in Africa (Ezeh, 1993; Agyei \& Migadde, 1995). While involving men in women's reproductive health has clear benefits, it must also be acknowledged that involving men compromises women's sexual and reproductive autonomy and exposes them to men's possible interference in their sexual and reproductive decision-making since if men are against abortion or they want more children than women, if the man knows about her desire to abort, he may interfere. This interference may include attempts by men to prevent the woman from accessing an abortion, or potentially, postabortion care (Moore et al. 2010).

Involving men in family planning holds the potential of reducing unintended pregnancy and thereby the demand for abortion. Work that Kaida et al. (2005) carried out in Mpigi district, Uganda, found that men have limited knowledge about family planning and that there is poor spousal communication about family planning in general, yet men want to be involved in family planning. This is a hopeful sign that men are interested in being included in the reproductive health sphere. The authors concede, however, that there remains a disjuncture between men's stated willingness and the reality of their actual participation in family planning programs (Kaida et al. 2005). Efforts have been made in other country contexts including Egypt and Tanzania to utilize men's involvement to proactively improve women's postabortion care-seeking (Abdel-Tawab et al., 1999; Rasch \& 
Lyaruu 2005). Therefore, while it is important to proceed cautiously in efforts to increase men's involvement, models exist to encourage male involvement in abortion.

Future research would do well to unpack Ugandan men's gender roles and social scripts that are contributing to their stated attitudes towards women who have abortions and who require abortion care (Greene 2000). Such an unpacking of men's abortion attitudes may identify ways to address the root causes of men's widespread opposition to abortion as well as provide recommendations for how men could help protect women's health within the confines of men's commonly held attitudes and beliefs. Furthermore, to the extent that men adhere to an antiabortion rhetoric but perhaps act differently in private is another area of inquiry.

In the Burkinábe context, Rossier noted that men's attitudes about abortion have not kept pace with women's lived experiences. She argues, "Abortion is kept a secret by women, not because it is a form of transgression nor from an awareness of having committed a socially condemned act, but in order to manage their public image in a society where social norms have not caught up with actual behavior" (Rossier, 2007: 237). The same could perhaps be said of Uganda since in December 2003, Uganda signed the African Charter on Human and People's Rights on the Rights of Women in Africa. That charter specifies that women have the right to control their fertility; to decide whether to have children; to decide on the number and spacing of their children; to obtain adequate, 
affordable and accessible health services; and to access medical abortion in cases of sexual assault, rape, incest, danger to the mental and physical health of the mother, and danger to the life of the mother or the fetus (African Union, 2003). Uganda's endorsement of the African Charter suggests that Uganda's abortion law, just as in Burkina Faso, may be out of step with prevailing public will, or at the very least, the country's political will, and that the time may be ripe to revisit the law dictating the provision of legal abortion in Uganda. Until then, programs that seek to redress some of the gender inequalities that inhibit men's support for women's pregnancy termination decisions and treatment for complications which can arise in a setting where abortion is highly restricted may help protect women's reproductive health. We hope that the day will come when men express greater compassion for women's reproductive predicaments and participate as respectful collaborators in women's reproductive health. 


\section{References}

Abdel-Tawab, N., Huntington, D., Hassan, E. O., Youssuf, H. \& Nawar, L. (1999) Effects of husband involvement on postabortion patients' recovery and use of contraception in Egypt. In Huntington, D. \& Piet-Pelon, N. J. (eds) Postabortion Care: Lessons from Operations Research. Population Council, New York, pp. 16-37.

African Union (2003) Protocol to the African Charter on Human and People's Rights on the Rights of Women in Africa. URL: http://www.achpr.org/english/ info/women en.html (accessed 26th January 2006).

Agyei, W. K. A. \& Migadde, M. (1995) Demographic and sociocultural factors influencing contraceptive use in Uganda. Journal of Biosocial Science 27, 47-60.

Atuyambe, L., Mirembe, F., Johansson, A., Kirumira, E. K. \& Faxelid, E. (2005) Experiences of pregnant adolescents - voices from Akiso district, Uganda. African Health Sciences 5, 304-309.

Brookman-Amissah, E. \& Moyo, J. B. (2004) Abortion law reform in SubSaharan Africa: no turning back. Reproductive Health Matters 12 (24 Supplement), 227-234.

Chikovore, J., Lindmark, G., Nystrom, L. \& Mbizvo, M. T. (2002) The hideand-seek game: men's perspectives on abortion and contraceptive use within marriage in a rural community in Zimbabwe. Journal of Biosocial Science 34, 317-332.

Dudgeon, M. R. \& Inhorn, M. C. (2004) Men's influences on women's reproductive health: medical anthropological perspectives. Social Science \& Medicine 59, 1379-1395.

Ezeh, A. C. (1993) The influence of spouses over each other's contraceptive attitudes in Ghana.Studies in Family Planning 24, 163-174.

Family Care International (1999) Meeting the Cairo Challenge: Progress in Sexual and Reproductive Health. FCl, New York.

Fayorsey, C. (1989) Family planning in Africa; the relevance of gender issues. In Developments in Family Planning Policies and Programmes in Africa. Regional Institute for Population, Legon, Ghana, pp. 194-229.

Greene, M. E. (2000) Changing women and avoiding men: gender stereotypes and reproductive health programmes. IDS Bulletin 31, 49-59. 
Gürsoy, A. (1996) Abortion in Turkey: a matter of state, family or individual decision. Social Science \& Medicine 42, 531-542.

Guttmacher Institute (2010) Facts on Induced Abortion in the United States. In brief. Guttmacher Institute, New York.

Jagwe-Wadda, G., Moore, A. M. \& Woog, V. (2006) Abortion Morbidity in Uganda: Evidence from Two Communities. Occasional Report No. 26, G uttmacher Institute, New York.

Kaida, A., Kipp, W., Hessel, P. \& Konde-Lule, J. (2005) Male participation in family planning: results from a qualitative study in Mpigi District, Uganda. Journal of Biosocial Science 37, 269-286.

Kyomuhendo, G. B. (2003) Low use of rural maternity services in Uganda: impact of women's status, traditional beliefs and limited resources. Reproductive Health Matters 11, 16-26.

Mbizvo, M. T. \& Adamchak, D. J. (1991) Family planning knowledge, attitudes and practice of men in Zimbabwe. Studies in Family Planning 22, 31-38.

Ministry of Finance and Economic Planning (1995) National Population Policy for Sustainable Development. Kampala, Uganda.

Moore, A. M., Frohwirth, L. F. \& Miller, E. (2010) Male reproductive control of women who have experienced intimate partner violence in the United States. Social Science \& Medicine 70, 1737-1744.

Nyanzi, S., Nyanzi, B. \& Bessie, K. (2005) 'Abortion? That's for women!' Narratives and experiences of commercial motorbike riders in SouthWestern Uganda. African Journal of Reproductive Health 9, 142-161.

Prada, E., Mirembe, F., Ahmed, F. H., Nalwadda, R. \& Kiggundu, C. (2005) Abortion and Post-abortion Care in Uganda: A Report from Health Care Professionals and Health Facilities. Occasional Report No. 17, Guttmacher Institute, New York.

Rasch, V. \& Lyaruu, M. A. (2005) Unsafe abortion in Tanzania and the need for involving men in postabortion contraceptive counseling. Studies in Family Planning 36, 301-310.

Republic of Uganda (2008) Road Map for Accelerating the Reduction of Maternal and Neonatal Mortality and Morbidity in Uganda 2006-2015. Republic of Uganda. 
Rossier, C. (2007) Abortion: an open secret? Abortion and social network involvement in Burkina Faso. Reproductive Health Matters 15, 230-238.

Singh, S., Moore, A. M., Bankole, A., Mirembe, F., Wolf, D. \& Prada, E. (2006) Unintended Pregnancy and Induced Abortion in Uganda: Causes and Consequences. Guttmacher Institute, New York.

Singh, S., Prada, E., Mirembe, F. \& Kiggundu, C. (2005) The incidence of induced abortion in Uganda. International Family Planning Perspectives 31, 183-191.

Thaddeus, S. \& Maine, D. (1994) Too far to walk: maternal mortality in context. Social Science \& Medicine 38, 1091-1110.

Uganda Bureau of Statistics \& Macro International (2007) Uganda Demographic and Health Survey 2006. UBOS and Macro International Inc., Calverton, MD, USA.

Weeks, A., Lavender, T., Nazziwa, E. \& Mirembe, F. (2005) Personal accounts of 'near-miss' maternal mortalities in Kampala, Uganda. British Journal of Obstetrics and Gynaecology 112, 1302-1307.

World Bank (2009) World Development Report 2009: Reshaping Economic Geography. The World Bank, Washington, DC.

World Health Organization (2007a) Maternal Mortality in 2005: Estimates Developed by WHO, UNICEF, UNFPA, and the World Bank. WHO, Geneva.

World Health Organization (2007b) Unsafe Abortion: Global and Regional Estimates of Incidence of Unsafe Abortion and Associated Mortality in 2003. WHO, Geneva. 
Table 1. Characteristics of women and men in-depth interview respondents

\begin{tabular}{|c|c|c|}
\hline & Women & Men \\
\hline Total N & 61 & 21 \\
\hline \multicolumn{3}{|l|}{ Age } \\
\hline $18-24$ & 13 & 3 \\
\hline $25-39$ & 19 & 11 \\
\hline $40-49$ & 10 & 7 \\
\hline $50-60$ & 19 & 0 \\
\hline \multicolumn{3}{|l|}{ Residence } \\
\hline Urban & 31 & 10 \\
\hline Rural & 30 & 11 \\
\hline \multicolumn{3}{|l|}{ Education* } \\
\hline None & 4 & 0 \\
\hline$<$ Secondary & 35 & 8 \\
\hline$\geq$ Secondary & 22 & 12 \\
\hline \multicolumn{3}{|l|}{ Marital status } \\
\hline Married/in union & 34 & 17 \\
\hline Not married/not in union & 27 & 4 \\
\hline \multicolumn{3}{|l|}{ Number of children } \\
\hline None & 2 & 1 \\
\hline $1-2$ & 16 & 5 \\
\hline $3-4$ & 13 & 8 \\
\hline 5 or more & 30 & 7 \\
\hline \multicolumn{3}{|l|}{ Religion } \\
\hline Muslim & 18 & 9 \\
\hline Christian & 41 & 11 \\
\hline Other & 2 & 1 \\
\hline
\end{tabular}

${ }^{*}$ For one male respondent, education level not specified (question not asked). 


\section{Acknowledgements}

The authors would like to thank Ellen M.H. Mitchell, Grace Bantebya

Kyomuhendo, Annika Johansson, Stella Neema, Patty Skuster, Susheela Singh, Vanessa Woog, Elena Prada, and an anonymous reviewer for the Journal of Biosocial Science for their constructive comments and suggestions on an earlier version of this manuscript. This work was made possible by the Netherlands Ministry for Development Cooperation, the World Bank and the UK Department for International Development. 